\title{
Efficient cellular solid-state NMR of membrane proteins by targeted protein labeling
}

\author{
Lindsay A. Baker ${ }^{1,2} \cdot$ Mark Daniëls $^{1} \cdot$ Elwin A. W. van der Cruijsen ${ }^{1} \cdot$ \\ Gert E. Folkers ${ }^{1} \cdot$ Marc Baldus ${ }^{1}$
}

Received: 12 February 2015/ Accepted: 23 April 2015/Published online: 9 May 2015

(c) The Author(s) 2015. This article is published with open access at Springerlink.com

\begin{abstract}
Solid-state NMR spectroscopy (ssNMR) has made significant progress towards the study of membrane proteins in their native cellular membranes. However, reduced spectroscopic sensitivity and high background signal levels can complicate these experiments. Here, we describe a method for ssNMR to specifically label a single protein by repressing endogenous protein expression with rifampicin. Our results demonstrate that treatment of $E$. coli with rifampicin during induction of recombinant membrane protein expression reduces background signals for different expression levels and improves sensitivity in cellular membrane samples. Further, the method reduces the amount of time and resources needed to produce membrane protein samples, enabling new strategies for studying challenging membrane proteins by ssNMR.
\end{abstract}

Keywords Solid-state NMR - Membrane protein . Cellular membranes · Protein expression

Lindsay A. Baker and Mark Daniëls have contributed equally to this work.

Electronic supplementary material The online version of this article (doi:10.1007/s10858-015-9936-5) contains supplementary material, which is available to authorized users.

Marc Baldus

m.baldus@uu.nl

1 NMR Spectroscopy, Department of Chemistry, Faculty of Science, Bijvoet Center for Biomolecular Research, Utrecht University, Padualaan 8, $3584 \mathrm{CH}$ Utrecht, The Netherlands

2 Present Address: Oxford Particle Imaging Centre, The Wellcome Trust Centre for Human Genetics, Division of Structural Biology, Nuffield Department of Medicine, University of Oxford, Roosevelt Drive, Oxford OX3 7BN, UK

\section{Introduction}

Membrane proteins (MPs) are often challenging to study by conventional structural biology methods and their native environment, a cellular membrane, is very heterogeneous and difficult to replicate in vitro. Although many membrane mimetics are available, the choice of mimetic can alter the biophysical properties of MPs (see, for example, Zhou and Cross 2013; Etzkorn et al. 2013). This phenomenon is one reason for the recent push towards crystallizing MPs in lipidic mesophases (Caffrey et al. 2012, for a review).

Solid-state nuclear magnetic resonance spectroscopy (ssNMR) is one method available to study the structure and dynamics of MPs in a lipid bilayer. ssNMR has been used successfully to determine the structure of membrane proteins (see, for example, Andronesi et al. 2005; Das et al. 2012; Wang et al. 2013a; van der Cruijsen et al. 2013), as well as investigating molecular interactions (Miao and Cross 2013, for a review) and function (Baker and Baldus 2014, for a review). However, most of these studies have used synthetic lipid bilayers, which can mimic the physical environment of cellular membranes but often lack their chemical heterogeneity. In addition to more closely resembling the cellular environment, the use of native membranes can remove the need to purify the MP of interest, eliminating any potential for structural disruptions during the solubilization process and speeding up sample preparation.

Several groups have demonstrated that ssNMR can be used to study structure and dynamics of proteins embedded in native lipid membranes (Etzkorn et al. 2007; Fu et al. 2011; Jacso et al. 2012; Miao et al. 2012; Kulminskaya et al. 2012; Ward et al. 2015). Previous work has demonstrated that it is possible to study MPs in cellular envelopes and 
whole cells of Escherichia coli by conventional (Renault et al. 2012b; Kaplan et al. 2015) and dynamic nuclear polarization (DNP)-enhanced ssNMR (Renault et al. 2012a; Yamamoto et al. 2014; Kaplan et al. 2015). In particular, we could show that studies using cellular envelopes or whole cells of Gram-negative bacteria are facilitated by use of a special E. coli deletion strain, to remove signals from naturally highly abundant outer MPs, i.e., OmpA and OmpF. In these preparations, signals from other cellular components, such as lipids, nucleotides, peptidoglycan and lipopolysaccharides, remain visible at intensities similar to that of the (overexpressed) protein of interest (Baldus 2015). Such non-proteinaceous correlations can help to refine the supramolecular structure of a protein in a membrane setting (see, e.g., Weingarth and Baldus 2013). Further, these signals can be used to study the structure of other molecular components such as RNA (Renault et al. 2012a) or material in the cell walls of bacteria and plants (DickPérez et al. 2011, 2012; Wang et al. 2012, 2014), as well as helping to clarify the cellular distribution of added reagents, such as radicals for DNP experiments (Takahashi et al. 2013).

On the other hand, these cellular signals can complicate the analysis of spectra of MPs that have not previously been characterized in synthetic bilayers. To reduce the challenges posed by the high background levels in cellular membrane samples, it would be beneficial to have a system by which isotope labels could be selectively incorporated into a MP of interest. Here, we demonstrate that treatment of cells with the antibiotic rifampicin, to inhibit the native RNA polymerase, produces native MP samples with significantly less background in ssNMR spectra. Previously, this concept was used for preparation of labeled proteins for solution-state NMR without purification (Almeida et al. 2001) with potential benefits to prevent cell lysis in the context of in-cell solution-state NMR experiments (Cruzeiro-Silva et al. 2006). During rifampicin treatment, the E. coli RNA polymerases are inhibited, preventing endogenous gene expression. However, systems for over-expression of proteins in $E$. coli, such as the $\mathrm{T} 7$ system, often use non-E. coli RNA polymerases that are not inhibited by rifampicin. If one induces expression of the heterologous protein after rifampicin treatment, the heterologous protein should be produced while endogenous protein production should decline. The suppression of endogenous protein production should direct any isotopically labeled nutrients towards heterologous protein production, hopefully resulting in an isotopically labeled target protein within a natural abundance cellular background. By coordinating the inhibition of endogenous gene expression with exposure to isotopically labeled media and induction of heterologous protein expression, rifampicin could provide a means to specifically isotopically label a heterologously expressed protein.
Using membrane proteins involved in protein insertion (YidC) with a high level of recombinant expression and ion transport (KcsA) exhibiting low level of recombinant expression, we show that this approach can be used to target labels to proteins of interest, resulting in spectral simplification and decreased isotope labeling costs. Further, the method also can be adapted to suit different labeling schemes and protein expression levels, and can be used efficiently even when the amount of recombinant protein is significantly less than that of major endogenous MPs [which have copy numbers of $\sim 10^{5}$ cell (Renault et al. $2012 \mathrm{~b}$ and references therein)]. By removing the need for high expression levels and purification of MPs, this method expands the applicability of ssNMR experiments to wider range of challenging MPs.

\section{Methods}

\section{Cloning and recombinant protein expression}

The gene for YidC from Escherichia coli (UniProt ID: $\mathrm{P} 25714)$ was cloned into pHisLic vector with an N-terminal $6 \times$ histidine tag for expression under a T7 system using enzyme-free cloning, as described previously (de Jong et al. 2006). The gene for KcsA from Streptomyces lividans (UniProt ID: P0A334) was obtained in a pT7 vector, as described previously (van Dalen et al. 2000). E. coli LEMO21 cells (New England Biolabs) were transformed with these plasmids by heat shock before plating on LB with ampicillin (AMP) at $50 \mu \mathrm{g} / \mathrm{mL}$ and chloramphenicol (CAM) at $35 \mu \mathrm{g} / \mathrm{mL}$. Cells were cultured according to standard practice (see also Baker et al. 2015). Precultures were grown in LB with AMP and CAM and then transferred to M9 minimal media (Folkers et al. 2004) supplemented with $1.0 \mathrm{~g} / \mathrm{L}{ }^{14} \mathrm{NH}_{4} \mathrm{Cl}, 5.0 \mathrm{~g} / \mathrm{L}^{12} \mathrm{C}_{6}$-glucose, AMP and CAM overnight. Between 50 and $500 \mathrm{~mL}$ volumes of M9, supplemented as above, were inoculated with the overnight cultures to OD 0.1 , and grown at $37^{\circ} \mathrm{C}$ with shaking until reaching an OD $\sim 1.5-2.0$. Cells were harvested by centrifugation at $4000 \times g$ for $15 \mathrm{~min}$ before resuspension in equal volumes isotopically labeled supplemented M9 $\left(1.0 \mathrm{~g} / \mathrm{L}{ }^{15} \mathrm{NH}_{4} \mathrm{Cl}, 5.0 \mathrm{~g} / \mathrm{L}{ }^{13} \mathrm{C}\right.$-glucose for uniformly labeled samples; $1.0 \mathrm{~g} / \mathrm{L}{ }^{14} \mathrm{NH}_{4} \mathrm{Cl}, 5.0 \mathrm{~g} / \mathrm{L}$ ${ }^{12} \mathrm{C}$-glucose and $200 \mathrm{mg} / \mathrm{L}$ each ${ }^{15} \mathrm{~N}$ and ${ }^{13} \mathrm{C}$ labeled amino acid for specifically labeled samples). IPTG (isopropyl $\beta$-D1-thiogalactopyranoside) at $0.5-1 \mathrm{mM}$ final concentration was added to induce expression of the $\mathrm{T} 7$ polymerase and the cultures were incubated at $28{ }^{\circ} \mathrm{C}$ for $30 \mathrm{~min}$ with shaking. Rifampicin was added to a final concentration of $100 \mu \mathrm{g} / \mathrm{mL}$ and the cultures were incubated with shaking in the dark at $28{ }^{\circ} \mathrm{C}$ overnight. Cells were harvested by centrifugation at $4000 \times g$ for $15 \mathrm{~min}$ at $4{ }^{\circ} \mathrm{C}$, and resuspended 
in 5-10 mL cold lysis buffer (20 mM Tris pH 7.4, $100 \mathrm{mM}$ $\mathrm{NaCl})$.

\section{Cellular membrane isolation, inner membrane purification, and SSNMR sample preparation}

Cells were lysed in a pressure cell homogenizer (Stansted) at 8000 psi without the addition of lysozyme. Cell debris was removed by centrifugation at $7000 \times g$ for $15 \mathrm{~min}$, and any inclusion bodies were removed, where necessary, by centrifugation at $25,000 \times g$ for $15 \mathrm{~min}$. Membranes were harvested by centrifugation at $100,000 \times g$ for $1 \mathrm{~h}$.

Inner and outer membrane fractions were separated with sucrose gradients (Baker et al. 2015). Briefly, $2 \mathrm{~mL}$ of $55 \%(\mathrm{w} / \mathrm{v})$ sucrose, $8 \mathrm{~mL}$ of $51 \%(\mathrm{w} / \mathrm{v})$ sucrose, $8 \mathrm{~mL}$ of $45 \%(\mathrm{w} / \mathrm{v})$ sucrose, and $5 \mathrm{~mL}$ of $36 \%(\mathrm{w} / \mathrm{v})$ sucrose, all in $50 \mathrm{mM}$ Tris $\mathrm{pH} 8.0$ buffer, were poured in a stepwise manner, with $4 \mathrm{~mL}$ of sample mixed with sucrose to a final concentration of $20 \%(\mathrm{w} / \mathrm{v})$ layered on top. The gradients were centrifuged overnight in a SW32-Ti swinging bucket rotor (Beckman) at $100,000 \times g$. Fractions corresponding to the outer membranes, inner membranes, and a mixture of outer and inner membranes were harvested with a syringe at the interface between the 55 and 51,45 and 36 , and 51 and $45 \%$ sucrose layers, respectively. The band of mixed outer and inner membranes was observed after growth in M9 media, but not after growth in LB.

Membranes were washed twice with buffer $(10 \mathrm{mM}$ phosphate buffer $\mathrm{pH} 6.8$ for YidC; 10 or $50 \mathrm{mM}$ phosphate buffer $\mathrm{pH} 7.0,10$ or $50 \mathrm{mM}$ potassium chloride, 10 or $50 \mathrm{mM}$ sodium chloride, and $0.01 \%$ sodium azide for KcsA inner and cellular membrane preparations, respectively) and collected by centrifugation at $125,000 \times g$ for $1-$ $2 \mathrm{~h}$ before packing into a $3.2 \mathrm{~mm}$ rotor for magic angle spinning (MAS).

\section{Purification of reference proteoliposome samples}

YidC with a hexa-histidine tag was over-expressed for purification as described for the cellular samples, with the following differences. After preculture, the main culture was inoculated in M9 with ${ }^{13} \mathrm{C}_{6}$-glucose and ${ }^{15} \mathrm{NH}_{4} \mathrm{Cl}$ at OD 0.1 , and grown to OD 0.6 prior to induction with IPTG and $10 \mu \mathrm{M}$ final concentration rhamnose. Rhamnose treated cells were found to produce more YidC when induced at lower ODs; no improvement was observed for induction at higher ODs like those used for rifampicin treatment. Cells were grown at $37{ }^{\circ} \mathrm{C}$ for a further $3-5 \mathrm{~h}$ until the OD was greater than 2.0. Cells were pelleted and lysed, and the membranes isolated as described for the cellular NMR samples. Membranes were solubilized at $4{ }^{\circ} \mathrm{C}$ by stirring with $2 \%$ (w/v) dodecyl maltoside (DDM) (Anatrace) in $10 \mathrm{mM}$ phosphate buffer (pH 6.8) containing
$250 \mathrm{mM} \mathrm{NaCl}, 2 \mathrm{mM}$ 2-mercaptoethanol, $10 \% \quad(\mathrm{v} / \mathrm{v})$ glycerol, $0.03 \%$ (w/v) DDM and $20 \mathrm{mM}$ imidazole (Buffer A) for $2 \mathrm{~h}$. Insoluble material was pelleted at $100,000 \times g$ for $1 \mathrm{~h}$, and the supernatant was bound to $5 \mathrm{~mL}$ Ni-NTA resin (Qiagen) overnight. The resin was washed with 4 column volumes $(\mathrm{CV})$ of buffer $\mathrm{A}$, and then with 2 $\mathrm{CV}$ of buffer B (10 mM phosphate buffer $\mathrm{pH} 6.8,100 \mathrm{mM}$ $\mathrm{NaCl}, 2 \mathrm{mM}$ 2-mercaptoethanol, $10 \%$ (v/v) glycerol, $0.03 \%(\mathrm{w} / \mathrm{v}) \mathrm{DDM}$ and $20 \mathrm{mM}$ imidazole). YidC was eluted with $5 \mathrm{CV}$ of buffer B with $380 \mathrm{mM}$ additional imidazole. The eluent was dialyzed four times for $\sim 2 \mathrm{~h}$ against $75 \mathrm{~mL}$ of Buffer B without imidazole. The protein concentration was estimated using the BCA assay (Pierce) and then mixed with E. coli polar lipid extract (Avanti Polar Lipids), dissolved in water, at a ratio of $2 \mathrm{mg}$ YidC: $1 \mathrm{mg}$ lipid. DDM was removed by overnight incubation with BioBeads (BioRad) and YidC proteoliposomes were harvested by centrifugation at $100,000 \times g$ for $1 \mathrm{~h}$. The proteoliposomes were washed in $10 \mathrm{mM}$ phosphate buffer, $\mathrm{pH} 6.8$, and pelleted at $125,000 \times g$ for $\sim 2 \mathrm{~h}$ before being packed into a $3.2 \mathrm{~mm}$ MAS rotor.

KcsA was over-expressed, purified, and reconstituted as described previously (Lange et al. 2006; van der Cruijsen et al. 2013).

\section{Spectroscopy, processing, and referencing}

All YidC samples were measured on a $700 \mathrm{MHz}$ narrow-bore spectrometer (Bruker Biospin, Germany) with a $3.2 \mathrm{~mm}{ }^{1} \mathrm{H}$, ${ }^{13} \mathrm{C},{ }^{15} \mathrm{~N}$ MAS probe at $13 \mathrm{kHz}$ MAS frequency, unless otherwise noted, and with a set temperature of $258 \mathrm{~K}$ (corresponding to an effective temperature of $\sim 4{ }^{\circ} \mathrm{C}$ ). HartmannHahn ${ }^{1} \mathrm{H}-{ }^{15} \mathrm{~N}$ and ${ }^{1} \mathrm{H}-{ }^{13} \mathrm{C}$ cross polarization $(\mathrm{CP})$ used contact times of 650 and $500 \mu \mathrm{s}$, respectively, and 70-100\% ramps. ${ }^{15} \mathrm{~N}-{ }^{13} \mathrm{C}$ SPECIFIC CP (Baldus et al. 1998) used a contact time of $4500 \mu$ s with optimized irradiation frequencies of 30.3 and $19 \mathrm{kHz}$, for ${ }^{15} \mathrm{~N}$ and ${ }^{13} \mathrm{C}$, respectively, and a ramp of 90-100\%. PARIS (Weingarth et al. 2009) was used for ${ }^{13} \mathrm{C}-{ }^{13} \mathrm{C}$ mixing, with a mixing time of $30 \mathrm{~ms}, 7.3 \mathrm{kHz}{ }^{1} \mathrm{H}$ irradiation, and MAS frequency of $11 \mathrm{kHz}$. In all experiments, decoupling used SPINAL64 (Fung et al. 2000) with ${ }^{1} \mathrm{H}$ irradiation of $83 \mathrm{kHz} .{ }^{15} \mathrm{~N}$-edited ${ }^{13} \mathrm{C}-{ }^{13} \mathrm{C}$ detected experiments used Hartmann-Hahn ${ }^{1} \mathrm{H}-{ }^{15} \mathrm{~N}$ CP followed by ${ }^{15} \mathrm{~N}-{ }^{13} \mathrm{C}_{\alpha}$ SPECIFIC CP and PARIS mixing.

KcsA samples were measured on an $800 \mathrm{MHz}$ widebore spectrometer (Bruker BioSpin, Germany) with a $3.2 \mathrm{~mm}{ }^{1} \mathrm{H},{ }^{13} \mathrm{C},{ }^{15} \mathrm{~N}$ MAS probe. Experiments were recorded at a set temperature of $253 \mathrm{~K}$ and MAS frequency of $12 \mathrm{kHz}$. CP contact times were $400 \mu$ s with a ramp of $70-100 \%$ for ${ }^{1} \mathrm{H}-{ }^{15} \mathrm{~N}$, SPECIFIC CP used $3000 \mu$ s contact time with 90-100\% ramp, and irradiation of 57, 38, and $29 \mathrm{kHz}$ was used for ${ }^{1} \mathrm{H},{ }^{15} \mathrm{~N}$, and ${ }^{13} \mathrm{C}$ pulses, respectively. Decoupling used SPINAL64 with $83.3 \mathrm{kHz}$ irradiation. 
Spectra were referenced against adamantane (Harris et al. 2008) and histidine (Wei et al. 1999) powders. Data were processed with TopSpin 3.0 (Bruker Biospin) and analyzed using Sparky (Goddard and Kneller 2008). Chemical shift predictions were made with Shiftx2 (Neal et al. 2003) and FANDAS (Gradmann et al. 2012) using atomic model PDB ID 3wvf (Kumazaki et al. 2014).

\section{Results and discussion}

To study the effect of adding rifampicin during cellular protein production and to assess the influence of ssNMR signals stemming from background molecules on our spectra, we conducted a series of ssNMR experiments using different sample preparation strategies for the case of high (YidC) and low (KcsA) protein expression. As a first target, we selected YidC, an $\sim 61 \mathrm{kDa}$ inner membrane protein from $E$. coli, that could be overexpressed during rifampicin treatment at sufficient levels to be observed clearly by SDSPAGE (denaturing polyacrylamide gel electrophoresis) in crude cell lysate (Fig. 1a). On the other hand, expression of the tetrameric $64 \mathrm{kDA}$ KcsA channel was visible but significantly lower (Fig. 1b) compared to the band corresponding to the highly naturally abundant (Renault et al. 2012b) outer membrane proteins OmpF and OmpA (denoted as OMP in Fig. 1a, b). SDS-PAGE will show all proteins

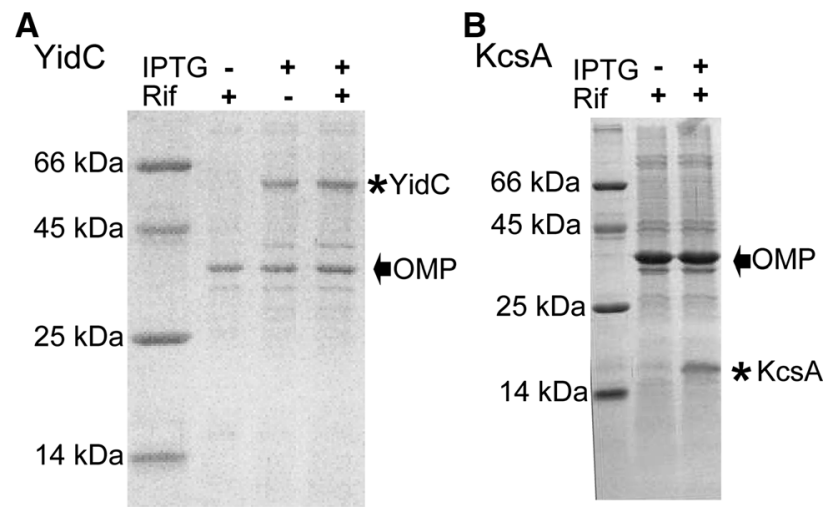

Fig. 1 Rifampicin can be used to selectively over-express membrane proteins. YidC and KcsA were overexpressed in E. coli LEMO cells during treatment with rifampicin, as seen by SDS-PAGE of crude cell lysate on a 12.5 and $13.75 \%$, respectively, acrylamide gel. a YidC: First lane marker; second lane without induction (-IPTG) and with rifampicin (+Rif) treatment; third lane with induction (+IPTG) but without rifampicin (-Rif); fourth lane with induction (+IPTG) and rifampicin (+Rif). b KcsA: First lane marker; second lane without induction (-IPTG) and with rifampicin (+Rif) treatment; fourth lane with induction (+IPTG) and rifampicin (+Rif). The band corresponding to YidC in a and KcsA in b is marked (asterisk), as is the band corresponding to the highly naturally abundant outer membrane proteins (OMP). OmpF and OmpA would run at this expected molecular weight, however, there is some overlap between OMPs (Renault et al. 2012b) present in the cellular membrane sample, not just those that are isotopically labeled. Therefore, to establish whether the targeted isotopic labeling was successful, we examined the cellular membrane samples by ssNMR.

We first examined fully $\left({ }^{13} \mathrm{C},{ }^{15} \mathrm{~N}\right)$ isotopically labeled YidC in the cellular membrane samples prepared with rifampicin and IPTG by ssNMR in a ${ }^{15} \mathrm{~N}-{ }^{13} \mathrm{C}_{\alpha}$ correlation CP-based spectrum (Fig. 2a, red) and compared our data to results obtained using purified YidC proteoliposomes (Fig. 2a, grey). Approximately $50 \mathrm{~mL}$ of culture at OD 2.0 was needed to fill a $3.2 \mathrm{~mm}$ MAS rotor with isolated cellular membranes. Using large exponential line broadening during processing, we obtained an overall insight into the NCA signatures of purified YidC in reference to the cellular sample with rifampicin. Within the resolution expected for a 548 amino-acid membrane protein, both preparations resulted in similar spectra. Subsequently, we prepared YidC cell envelopes without rifampicin (Fig. 2b, blue), to elucidate the effect of background signals on the interpretation of the cellular membrane samples. Without rifampicin, additional signals were observed. The difference in signal can clearly be seen by comparing projections of the ${ }^{15} \mathrm{~N}-{ }^{13} \mathrm{C}_{\alpha}$ correlation spectrum (Fig. 2d). These additional signals can be attributed to isotopic labels incorporated in a non-specific manner, reflecting the diversity of proteins being produced during induction and continued cell growth. Finally, we prepared samples with rifampicin but without IPTG, to determine the amount of background signals actually present in the rifampicin-treated cellular membrane preparations (Fig. 2c, green). In this case, only a very low level of background was detected. The spectrum for each of the cellular membrane samples was recorded and processed with identical conditions. Taken together, these results suggest that the rifampicin treatment improves the detection of YidC in a cellular membrane context in ${ }^{15} \mathrm{~N}-{ }^{13} \mathrm{C}_{\alpha}$ correlation spectra.

The potential for the use of ${ }^{13} \mathrm{C}-{ }^{13} \mathrm{C}$ correlation spectra also was explored; however, due to the high levels of ${ }^{13} \mathrm{C}$ labeled phospholipids in the fully labeled cellular membrane samples, we performed ${ }^{15} \mathrm{~N}$-edited ${ }^{13} \mathrm{C}-{ }^{13} \mathrm{C}$ correlation CP-based experiments in which SPECIFIC CP transfer (Baldus et al. 1998) from ${ }^{15} \mathrm{~N}$ to ${ }^{13} \mathrm{C}_{\alpha}$ nuclei is followed by a PARIS mixing block to detect aliphatic $\mathrm{C}_{\alpha}-\mathrm{C}_{\mathrm{x}}$ correlations in a two-dimensional $\left({ }^{13} \mathrm{C},{ }^{13} \mathrm{C}\right)$ correlation experiment (Fig. 3a). In Fig. 3b, results of such an experiment for YidC (red) are compared to data obtained using a non-edited ${ }^{13} \mathrm{C}-{ }^{13} \mathrm{C}$ correlation $\mathrm{CP}$-based experiment with reconstituted YidC liposomes (grey). Although the spectral overlap was reduced compared to the ${ }^{15} \mathrm{~N}-{ }^{13} \mathrm{C}_{\alpha}$ spectra, the sensitivity of the ${ }^{15} \mathrm{~N}$-edited experiment was limited, possibly due to signal loss during the additional magnetization transfer step in comparison to non- ${ }^{15} \mathrm{~N}$-edited experiments. 

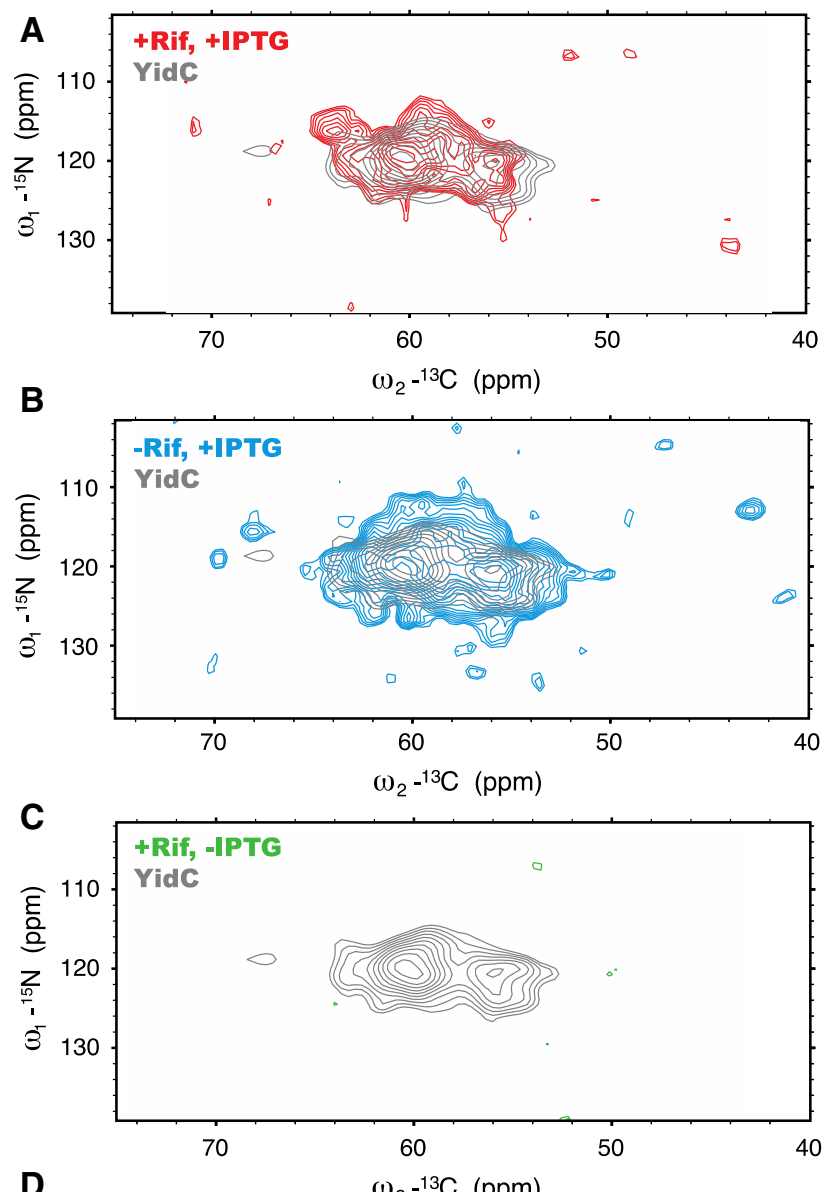

D

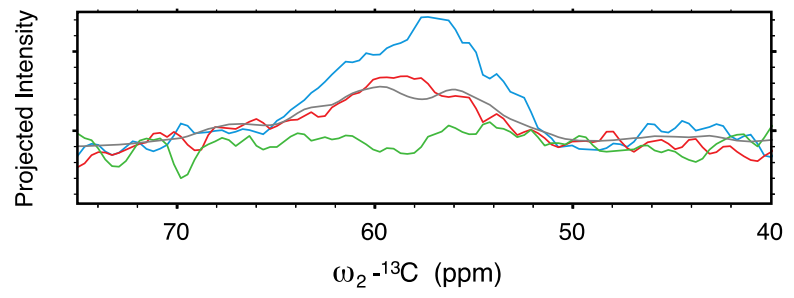

Fig. $2{ }^{15} \mathrm{~N}-{ }^{13} \mathrm{C}_{\alpha}$ CP-based correlation spectra of YidC in a cellular membranes with IPTG and rifampicin (red), b cellular membranes without rifampicin but with IPTG (blue), and c cellular membranes with rifampicin and without IPTG (green). The spectrum of YidC after purification and reconstitution into $E$. coli lipid extract proteoliposomes is shown in grey in each panel with the same processing as the cellular membrane samples. All spectra were collected with a $350 \mu$ s increment for $6 \mathrm{~ms}$ acquisition time in the indirect dimension and $8 \mathrm{~ms}$ acquisition in the direct, averaged over 1072 scans, and processed after zero-filling without linear prediction with $150 \mathrm{~Hz}$ line broadening. The lowest contour levels were set as $\sim 2.7 \times$ the standard deviation of the noise in the cellular membrane samples. The lowest contour level for the spectrum of purified YidC was chosen to keep the number and spacing of contours the same as for the cellular membrane samples. d Each spectra in a-c was projected onto the ${ }^{13} \mathrm{C}$ plane in order to compare total signal between samples with and without rifampicin and IPTG. Red with IPTG and rifampicin; blue with IPTG and without rifampicin; green without IPTG and with rifampicin; grey purified YidC, scaled to the same range as the spectrum of cellular membranes with rifampicin and IPTG $(r e d)$
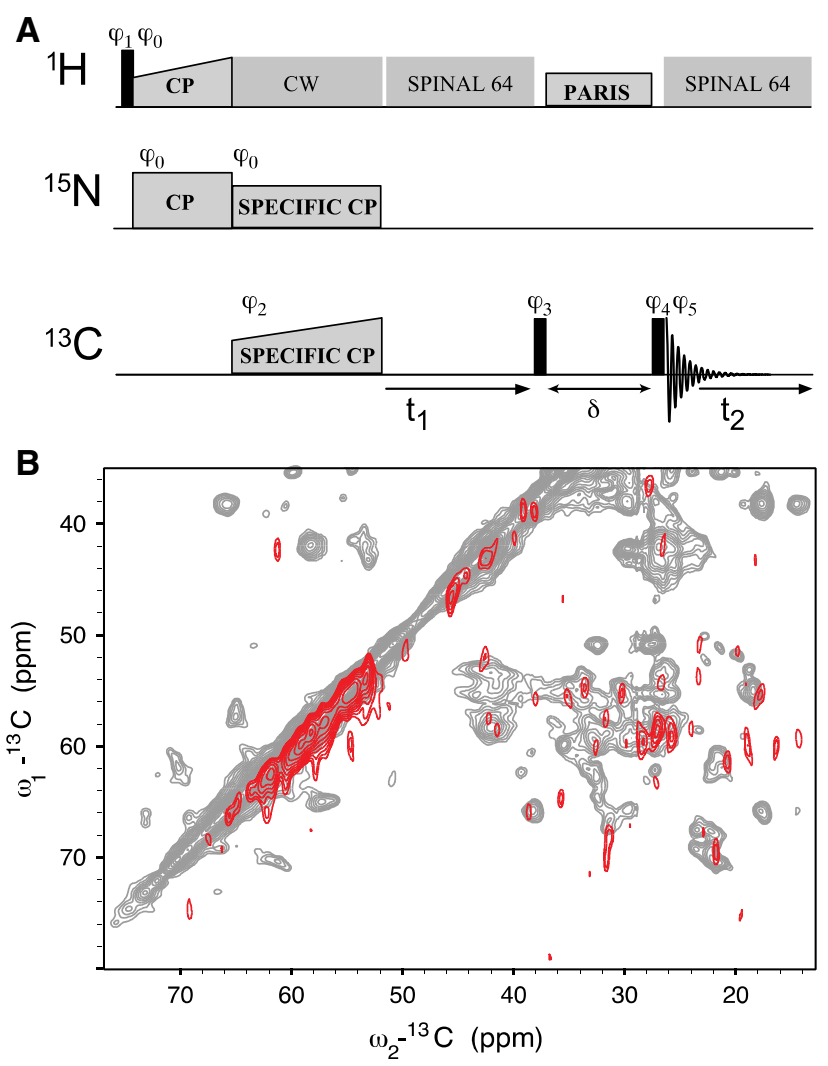

Fig. 3 a Schematic diagram of pulse sequence used for CP-based ${ }^{15} \mathrm{~N}$-edited ${ }^{13} \mathrm{C}-{ }^{13} \mathrm{C}$ correlation spectra. After $\mathrm{CP}$-based transfer from ${ }^{1} \mathrm{H}$ to ${ }^{15} \mathrm{~N}$, Specific $\mathrm{CP}$ is used to transfer to ${ }^{13} \mathrm{C}_{\alpha}$ (with field offset $\Delta \omega)$, followed by a PARIS mixing block of length $\delta$. Continuous wave $(\mathrm{CW})$ and SPINAL 64 decoupling schemes were used as indicated. The phase cycling follows $\varphi_{0}=(0), \quad \varphi_{1}=(13)$, $\varphi_{2}=(0022), \varphi_{3}=(3), \varphi_{4}=\left(\begin{array}{ll}0000 & 1111 \\ 2222 & 3333\end{array}\right), \varphi_{5}=(0220$ 13312002 3113). b A ${ }^{13} \mathrm{C}-{ }^{13} \mathrm{C}$ correlation spectrum of fully isotopically labeled membrane protein YidC (red) was recorded with ${ }^{15} \mathrm{~N}$ editing to remove signal from lipids. A CP-based ${ }^{15} \mathrm{~N}$-edited ${ }^{13} \mathrm{C}-{ }^{13} \mathrm{C}$ PARIS (30 ms mixing) correlation spectrum of YidC in rifampicin cellular membranes was collected with a $114 \mu$ s increment for $2.5 \mathrm{~ms}$ total acquisition time in the indirect dimension and $10 \mathrm{~ms}$ acquisition in the direct, averaged over 2800 scans, and processed after zero-filling without linear prediction with a line broadening of $75 \mathrm{~Hz}$. This experiment was extremely insensitive in comparison to a CP-based ${ }^{13} \mathrm{C}-{ }^{13} \mathrm{C}$ PARIS (30 ms mixing) correlation spectrum of purified YidC and E. coli lipid proteoliposomes, overlaid in grey as a reference

To further reduce spectral contributions from non-proteinaceous cellular components for samples prepared with ${ }^{13} \mathrm{C}$ glucose, we used the rifampicin treatment protocol to label specific amino acids, as described in "Materials and methods". Incorporation of isotopes through the addition of labeled amino acids significantly reduces the background signal from lipids, but it does not reduce the incorporation of isotopes into endogenous proteins. Although the background signal will be less than in a uniformly labeled sample, as fewer amino acids are labeled, use of rifampicin will still block the incorporation of labeled 

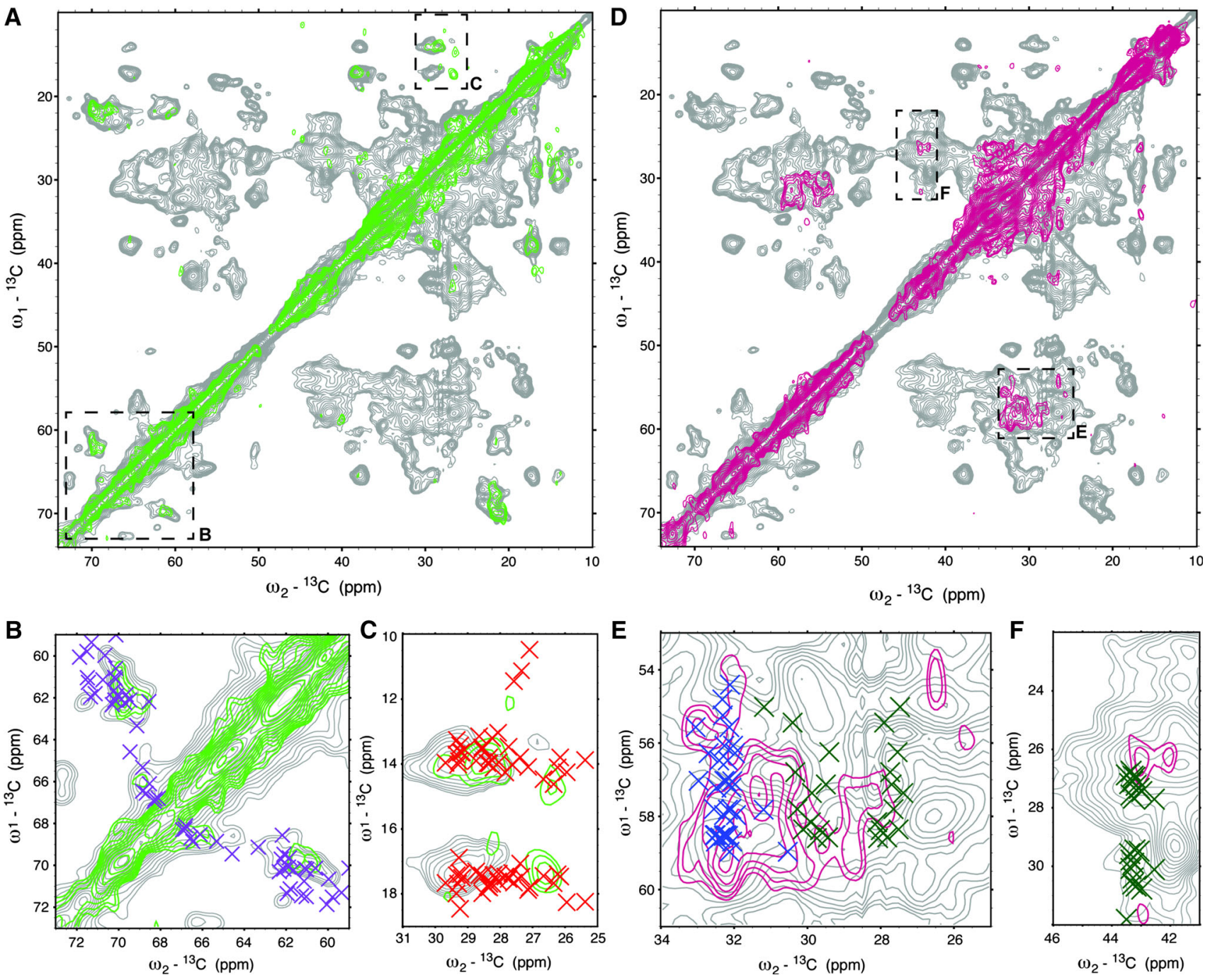

Fig. 4 Spectra of large membrane proteins can be improved with specific amino acid labeling. a, d CP-based ${ }^{13} \mathrm{C}-{ }^{13} \mathrm{C}$ PARIS $(30 \mathrm{~ms}$ mixing) correlation spectra of YidC in rifampicin cellular membranes that are threonine and isoleucine labeled (green), and methionine and arginine labeled (pink). In both spectra, a CP-based ${ }^{13} \mathrm{C}-{ }^{13} \mathrm{C}$ PARIS (30 ms mixing) correlation spectra of purified YidC in E. coli lipid proteoliposomes is overlaid in grey. b, c Magnified views of the boxed areas in a. Although threonine (predicted resonances shown as purple crosses) and isoleucine (predicted resonances shown as red crosses) comprise only $\sim 13 \%$ of the residues in YidC, there is sufficient resolution and sensitivity in ${ }^{13} \mathrm{C} \mathrm{CP}$-based spectra to separate threonine residues with alpha helical and beta-strand secondary structure. e, f Magnified views of the boxed areas in

amino acids into endogenous proteins. Two YidC cellular membrane samples were prepared with different amino acid combinations, chosen to avoid unintentional labeling of additional amino acids via metabolic scrambling. In these specifically labeled samples, background lipid signals were negligible, and ${ }^{13} \mathrm{C}-{ }^{13} \mathrm{C}$ correlation experiments could be used without ${ }^{15} \mathrm{~N}$-editing steps (Fig. 4). In the threonine and isoleucine labeled sample (Fig. $4 \mathrm{a}$ and d. Methionine predicted resonances are shown as blue crosses and arginine predicted resonances as green crosses. In the Met-Arg labeled cell envelopes, only $\sim 6 \%$ of residues are labeled, and hence the sensitivity is less than that of the Thr-Ile labeled. The spectra were recorded with a $40 \mu \mathrm{s}$ increment and 3 and $8 \mathrm{~ms}$ total acquisition time in the indirect and direct dimensions, respectively, averaged over 176 and 272 scans for $(\mathbf{a}-\mathbf{c})$ and $(\mathbf{d}-\mathbf{f})$, respectively, and processed after zero-filling without linear prediction with a line broadening of $75 \mathrm{~Hz}$. Predicted correlations were calculated using ShiftX (Neal et al. 2003) and FANDAS (Gradmann et al. 2012) based on the recent crystal structure of YidC from E. coli [PDB ID $3 \mathrm{wvf}$ (Kumazaki et al. 2014)]

cutouts in Fig. 4b, c), 73 out of 548 residues were labeled $(\sim 13 \%)$, while in the methionine and arginine labeled sample (Fig. 4d with cutouts in Fig. 4e, f), 34 were labeled $(\sim 6 \%)$. For both samples, sensitivity was sufficient for a two-dimensional ${ }^{13} \mathrm{C}-{ }^{13} \mathrm{C}$ correlation $\mathrm{CP}$-based experiment with 30 or 150 ms PARIS mixing to be recorded with less than 300 scans per $t_{1}$ point. The spectra exclusively contained correlations expected for intra-residue atoms 
Fig. 5 Separation of inner and outer membranes improves the sensitivity of cellular membrane samples. ${ }^{15} \mathrm{~N}-{ }^{13} \mathrm{C}_{\alpha}$ CP-based correlation spectra of KcsA in cellular membranes (a blue) and inner membrane vesicles (b red) prepared with rifampicin, in comparison to purified and reconstituted KcsA (a, b grey). Each spectrum was recorded with a $350 \mu$ s increment to $6 \mathrm{~ms}$ total acquisition time in the indirect dimension and $8 \mathrm{~ms}$ total acquisition in the direct, averaged over 1072 scans, and processed after zero-filling without linear prediction with QSINE 3 and 2.5 in the direct and indirect dimensions, respectively. In $\mathbf{b}$, previously assigned resonances (Schneider et al. 2008; van der Cruijsen et al. 2013) that are functionally important and resolved in the inner membrane samples are indicated. The positions of the indicated residues with assigned resonances are indicated in red on the structure of KcsA (PDB 3EFF) in c, where the approximate membrane boundaries are shown as yellow lines. One subunit of KcsA is not shown for clarity
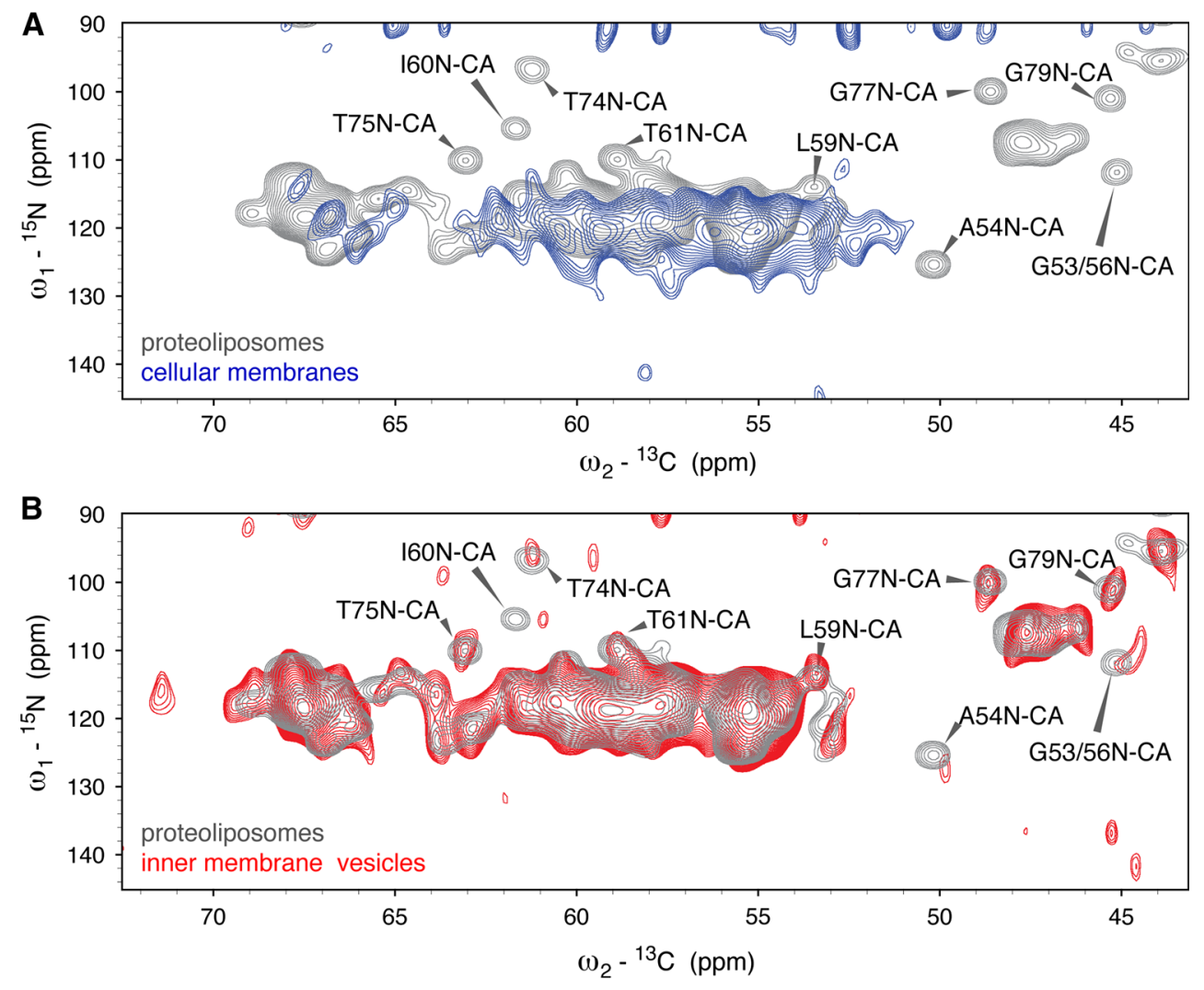

C

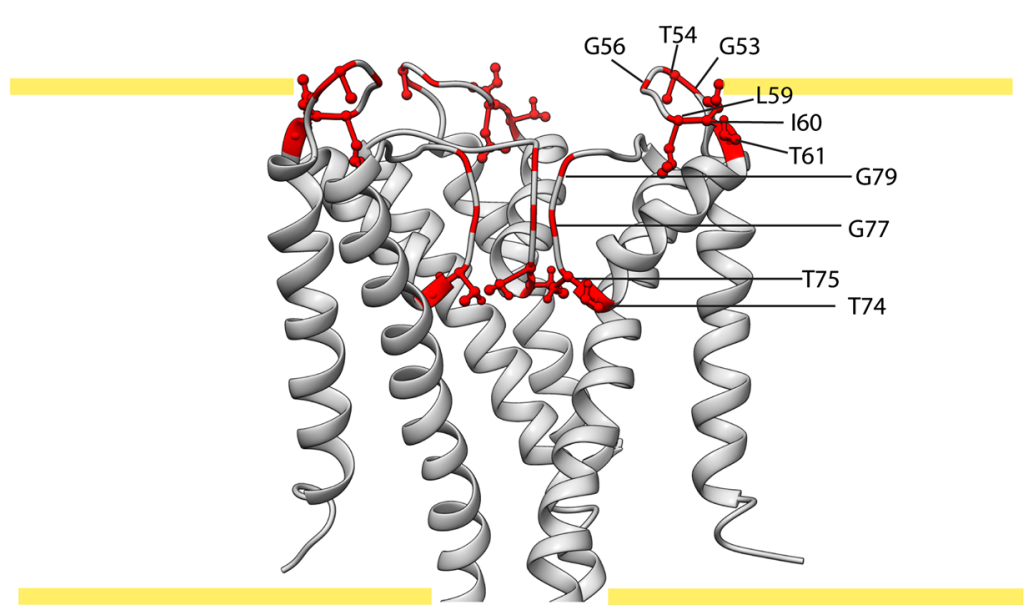

separated by 1 or 2 bonds (Thr, Ile, Fig. 4a, b) and (Met, Arg, Fig. 4d with cutout e, f). The observed resonance frequencies agreed with a spectrum obtained on uniformly labeled YidC proteoliposomes (Fig. 4, grey), and they were in line with predicted correlations using FANDAS (Gradmann et al. 2012) derived from the recent crystal structure of YidC (PDB ID 3wvf, (Kumazaki et al. 2014). The decrease in spectral crowding was significant.

To investigate whether rifampicin-based repression of endogenous expression allows for successful preparation of cellular membrane samples with MPs that have significantly lower expression levels than YidC, we prepared fully isotopically labeled cellular membrane samples for the potassium channel KcsA from $S$. lividans. As shown in Fig. 1b, in our expression system KcsA expresses in significantly lower amounts than both YidC and the endogenous outer membrane proteins (designated as OMP in Fig. 1), which are typically present in E. coli cells at copy numbers of $\sim 10^{5} /$ cell (Renault et al. 2012b, references therein). In Fig. 5a, we compare results of ${ }^{15} \mathrm{~N}-{ }^{13} \mathrm{C}_{\alpha}$ correlation experiments conducted on uniformly labeled cellular envelopes containing over-expressed KcsA (blue) to data obtained using reconstituted $\left({ }^{13} \mathrm{C},{ }^{15} \mathrm{~N}\right)$ labeled KcsA in asolectin liposomes for which assignments are available 
(Schneider et al. 2008; van der Cruijsen et al. 2013). Figure $5 \mathrm{a}$ suggests that cellular envelope preparations are dominated by other protein components, potentially stemming from outer membrane proteins such as $\mathrm{OmpA} / \mathrm{F}$, and LPP (outer membrane lipoprotein) that endogenously express to high levels (Stenberg et al. 2005; Renault et al. $2012 \mathrm{~b}$, and references therein). The resonances observed in the KcsA cellular membrane samples (Fig. 5a) are different to those observed in the YidC cellular membrane samples (Fig. 2a), as demonstrated in Supplementary Fig. 1a. Indeed, the observed ${ }^{15} \mathrm{~N}-{ }^{13} \mathrm{C}_{\alpha}$ correlation pattern from cellular envelope membranes (Fig. 5a, blue) shows striking overlap with that of purified Lpp (see Supplemental Figure 1B).

To remove signal from outer membrane proteins, we explored the use of inner membrane vesicles prepared from our cellular envelope samples. The sucrose gradient used to separate the inner and outer membrane resulted in a relatively low yield of inner membranes when cells were grown in M9 media, so $\sim 200 \mathrm{~mL}$ of cell culture at OD $\sim 2.0$ was needed to fill a $3.2 \mathrm{~mm}$ MAS rotor. However, the spectral quality of ${ }^{15} \mathrm{~N}-{ }^{13} \mathrm{C}_{\alpha}$ SPECIFIC CP-based experiments using inner membrane samples of KcsA was considerably improved compared to using cellular membrane samples (Fig. 5b). We could readily observe resolved peaks with previous assignments (Schneider et al. 2008; van der Cruijsen et al. 2013) to the turret region (such as T61) and selectivity filter (T74, T75 or G79) of KcsA in the fully labeled inner membrane samples (Fig. 5b, c). Interestingly, we observed reduced ssNMR intensities for T74, for which we have recently found increased dynamics in the closed-conductive state (Koers et al. 2014). The same applies to G53 and A54, which exhibit stronger dynamics compared to other regions of the turret, such as T61 (van der Cruijsen et al. in preparation). Given that the lipid character influences the function of KcsA channels in lipid bilayers (Weingarth et al. 2013), these data provide initial evidence for structural conservation of KcsA irrespective of whether membrane mimetics such as asolectin that is rich in the zwitterionic phosphatidyl choline (PC) or E. coli inner membranes (rich in zwitterionic phosphatidyl ethanolamine, PE) are used.

\section{Conclusions}

Studying complex molecules in their biological context is an exciting prospect for structural biology. There is increasing evidence that the environment is an important contributor to the biophysical properties of proteins, modulating important biological processes such as ligand binding (e.g. Hubbard et al. 2003) and protein-protein interactions (e.g. Burz et al. 2006). In-cell NMR has even revealed different protein folding states in vitro and in vivo
(Dedmon et al. 2002). For MPs, the impact of different environmental mimics has been well established in vitro. The difference between in vitro and in vivo experiments, however, is less well understood, due to the challenges of probing biological processes at an atomic level in a specific manner for these proteins. The work presented here expands the scope of cellular ssNMR to study the properties of MPs in their native environment. We have demonstrated that rifampicin treatment can be used to produce cellular membrane samples for ssNMR with specific protein labeling. Unlike in-cell NMR experiments where selective isotope incorporation was not found to significantly improve ${ }^{15} \mathrm{~N}$ experiments (Serber et al. 2001), we have demonstrated a clear improvement in ssNMR spectra of cellular membrane samples upon removal of background signals with rifampicin. This difference is most likely due to the use of direct ${ }^{13} \mathrm{C}$ detection in our ssNMR experiments. These samples can be adapted to different isotopic labeling schemes and protein expression levels. As demonstrated with KcsA, individual resonances, important for function, can be observed. Although the rifampicin treatment can only be used to inhibit bacterial RNA polymerases (Campbell et al. 2001), a method similar to the single protein production (SPP) system (Suzuki et al. 2005) could potentially be used with eukaryotic cells.

Expression, purification and reconstitution of MPs into synthetic lipid bilayers can be a slow process, often requiring several weeks for more complicated samples. $\mathrm{Pu}$ rification necessitates removing MPs from their native environment, which potentially induces structural changes and loss of activity. Some membrane proteins are not amenable to established purification methods, and nearly impossible to purify in large quantities. As such, any method that allows MPs to be characterized in their native environment not only augments the biological relevance of any observations, but also presents an opportunity to study previously intractable systems. This system also naturally lends itself to the study of MP complexes, which are often disrupted by detergent solubilization.

From a spectroscopic point of view, rifampicin-treated cellular membrane samples present some unique advantages. Assignment of resonances in MPs can be challenging and dedicated labeling schemes are usually needed to reduce spectral overlap (see, for example, Etzkorn et al. 2007; Shi et al. 2011; Wang et al. 2013b; Sinnige et al. 2015). Specific labeling of a small number of amino acids presents an additional means to aid ssNMR assignment for these larger MPs. Due to the large number of samples that must be prepared to exhaustively cover the protein, this method would be extremely time and resource intensive for purified proteins. Here we have demonstrated that it is possible to study MPs isotopically labeled at a small number of amino acids from small cell culture volumes 
$(\sim 50 \mathrm{~mL})$ without purification. This system does not rely on concentrating large cell cultures into small volumes before induction (as done in Mao et al. 2011), which in our hands results in lower expression levels of both membrane and soluble proteins. The rifampicin system presents a method by which to employ specific amino acid labeling quickly and inexpensively as an assignment strategy, potentially allowing ssNMR studies of membrane proteins which cannot be purified, of large membrane proteins with significant spectral overlap, and of membrane protein complexes.

Acknowledgments We thank Prof. A. Killian for the pT7-KcsA plasmid. LAB was supported by a Human Frontier Science Program Long Term Fellowship. This work was supported by NWO (Grants 700.10 .443 and 700.26 .121 to M.B.).

Open Access This article is distributed under the terms of the Creative Commons Attribution 4.0 International License (http:// creativecommons.org/licenses/by/4.0/), which permits unrestricted use, distribution, and reproduction in any medium, provided you give appropriate credit to the original author(s) and the source, provide a link to the Creative Commons license, and indicate if changes were made.

\section{References}

Almeida FC, Amorim GC, Moreau VH et al (2001) Selectively labeling the heterologous protein in Escherichia coli for NMR studies: a strategy to speed up NMR spectroscopy. J Magn Reson 148:142-146

Andronesi OC, Becker S, Seidel K et al (2005) Determination of membrane protein structure and dynamics by magic-angle-spinning solid-state NMR spectroscopy. J Am Chem Soc 127:574-581

Baker LA, Baldus M (2014) Characterization of membrane protein function by solid-state NMR spectroscopy. Curr Opin Struct Biol 27:48-55

Baker LA, Folkers GE, Sinnige T, et al (2015) Magic-angle-spinning solid-state NMR of membrane proteins. Methods Enzymol Ion Channels Part B 557:307-328. doi:10.1016/bs.mie.2014.12.023

Baldus M (2015) A solid view of membrane proteins in situ. Biophys J 108:1585-1586. doi:10.1016/j.bpj.2015.02.019

Baldus M, Petkova AT, Herzfeld J, Griffin RG (1998) Cross polarization in the tilted frame: assignment and spectral simplification in heteronuclear spin systems. Mol Phys 95:1197-1207

Burz DS, Dutta K, Cowburn D, Shekhtman A (2006) Mapping structural interactions using in-cell NMR spectroscopy (STINTNMR). Nat Methods 3:91-93

Caffrey M, Li D, Dukkipati A (2012) Membrane protein structure determination using crystallography and lipidic mesophases: recent advances and successes. Biochemistry 51:6266-6288

Campbell E, Korzheva N, Mustaev A et al (2001) Structural mechanism for rifampicin inhibition of bacterial RNA polymerase. Cell 104:901-912

Cruzeiro-Silva C, Albernaz F, Valente A, Almeida F (2006) In-Cell NMR spectroscopy: inhibition of autologous protein expression reduces Escherichia coli lysis. Cell Biochem Biophys 44:497-502. doi:10.1385/CBB:44:3:497
Das B, Nothnagel H, Lu G et al (2012) Structure determination of a membrane protein in proteoliposomes. J Am Chem Soc 134:2047-2056

De Jong RN, Daniëls MA, Kaptein R, Folkers GE (2006) Enzyme free cloning for high throughput gene cloning and expression. J Struct Funct Genomics 7:109-118. doi:10.1007/s10969-006-9014-z

Dedmon MM, Patel CN, Young GB, Pielak GJ (2002) FlgM gains structure in living cells. Proc Natl Acad Sci USA 99:12681-12684

Dick-Perez M, Wang T, Salazar A et al (2012) Multidimensional solidstate NMR studies of the structure and dynamics of pectic polysaccharides in uniformly 13C-labeled Arabidopsis primary cell walls. Magn Reson Chem 50:539-550. doi:10.1002/mrc.3836

Dick-Pérez M, Zhang Y, Hayes J et al (2011) Structure and interactions of plant cell-wall polysaccharides by two- and three-dimensional magic-angle-spinning solid-state NMR. Biochemistry 50:989-1000. doi:10.1021/bi101795q

Etzkorn M, Martell S, Andronesi OC et al (2007) Secondary structure, dynamics, and topology of a seven-helix receptor in native membranes, studied by solid-state NMR spectroscopy. Angew Chem Int Ed Engl 46:459-462. doi:10.1002/anie.200602139

Etzkorn M, Raschle T, Hagn F et al (2013) Cell-free expressed bacteriorhodopsin in different soluble membrane mimetics: biophysical properties and NMR accessibility. Structure 21:394-401

Folkers GE, van Buuren BNM, Kaptein R (2004) Expression screening, protein purification and NMR analysis of human protein domains for structural genomics. J Struct Funct Genomics 5:119-131. doi:10.1023/B:JSFG.0000029200.66197.0c

Fu R, Wang X, Li C et al (2011) In situ structural characterization of a recombinant protein in native Escherichia coli membranes with solid-state magic-angle-spinning NMR. J Am Chem Soc 133:12370-12373. doi:10.1021/ja204062v

Fung BM, Khitrin AK, Ermolaev K (2000) An improved broadband decoupling sequence for liquid crystals and solids. J Magn Reson 142:97-101

Goddard TD, Kneller DG (2008) SPARKY 3. University of California, San Francisco

Gradmann S, Ader C, Heinrich I et al (2012) Rapid prediction of multi-dimensional NMR data sets. J Biomol NMR 54:377-387

Harris RK, Becker ED, Cabral de Menezes SM et al (2008) Further conventions for NMR shielding and chemical shifts (IUPAC Recommendations 2008). Pure Appl Chem 80:59-84

Hubbard JA, MacLachlan LK, King GW et al (2003) Nuclear magnetic resonance spectroscopy reveals the functional state of the signalling protein $\mathrm{CheY}$ in vivo in Escherichia coli. Mol Microbiol 49:1191-1200

Jacso T, Franks WT, Rose H et al (2012) Characterization of membrane proteins in isolated native cellular membranes by dynamic nuclear polarization solid-state NMR spectroscopy without purification and reconstitution. Angew Chem Int Ed Engl 51:432-435. doi:10.1002/anie.201104987

Kaplan M, Cukkemane A, van Zundert GCP et al (2015) Probing a cell-embedded Megadalton protein complex by DNP-supported solid-state NMR. Nat Methods (in press)

Koers EJ, van der Cruijsen EAW, Rosay M et al (2014) NMR-based structural biology enhanced by dynamic nuclear polarization at high magnetic field. J Biomol NMR. doi:10.1007/s10858-0149865-8

Kulminskaya NV, Pedersen MØ, Bjerring M et al (2012) In situ solidstate NMR spectroscopy of protein in heterogeneous membranes: the baseplate antenna complex of Chlorobaculum tepidum. Angew Chem Int Ed Engl 51:6891-6895. doi:10.1002/anie.201201160

Kumazaki K, Kishimoto T, Furukawa A, et al (2014) Crystal structure of Escherichia coli YidC, a membrane protein chaperone and insertase. Sci Rep 4:7299 
Lange A, Giller K, Hornig S et al (2006) Toxin-induced conformational changes in a potassium channel revealed by solid-state NMR. Nature 440:959-962. doi:10.1038/nature04649

Mao L, Inoue K, Tao Y et al (2011) Suppression of phospholipid biosynthesis by cerulenin in the condensed single-proteinproduction (cSPP) system. J Biomol NMR 49:131-137

Miao Y, Cross TA (2013) Solid state NMR and protein-protein interactions in membranes. Curr Opin Struct Biol 23:919-928

Miao Y, Qin H, Fu R et al (2012) M2 proton channel structural validation from full-length protein samples in synthetic bilayers and E. coli membranes. Angew Chem Int Ed Engl 51:8383-8386. doi:10.1002/anie.201204666

Neal S, Nip AM, Zhang H, Wishart DS (2003) Rapid and accurate calculation of protein $1 \mathrm{H}, 13 \mathrm{C}$ and $15 \mathrm{~N}$ chemical shifts. J Biomol NMR 26:215-240

Renault M, Pawsey S, Bos MP et al (2012a) Solid-state NMR spectroscopy on cellular preparations enhanced by dynamic nuclear polarization. Angew Chem Int Ed Engl 51:2998-3001

Renault M, Tommassen-van Boxtel R, Bos MP et al (2012b) Cellular solid-state nuclear magnetic resonance spectroscopy. Proc Natl Acad Sci USA 109:4863-4868

Schneider R, Ader C, Lange A et al (2008) Solid-state NMR spectroscopy applied to a chimeric potassium channel in lipid bilayers. J Am Chem Soc 130:7427-7435. doi:10.1021/ja800190c

Serber Z, Ledwidge R, Miller S, Dötsch V (2001) Evaluation of parameters critical to observing proteins inside living Escherichia coli by in-cell NMR spectroscopy. J Am Chem Soc 123:8895-8901. doi:10.1021/ja0112846

Shi L, Kawamura I, Jung K et al (2011) Conformation of a sevenhelical transmembrane photosensor in the lipid environment. Angew Chem Int Ed Engl 50:1302-1305

Sinnige T, Houben K, Pritisanac I et al (2015) Insight into the conformational stability of membrane-embedded BamA using a combined solution and solid-state NMR approach. J Biomol NMR 61:321-332. doi:10.1007/s10858-014-9891-6

Stenberg F, Chovanec P, Maslen SL et al (2005) Protein complexes of the Escherichia coli cell envelope. J Biol Chem 280:34409-34419. doi:10.1074/jbc.M506479200

Suzuki M, Zhang J, Liu M et al (2005) Single protein production in living cells facilitated by an mRNA interferase. Mol Cell $18: 253-261$

Takahashi H, Ayala I, Bardet M et al (2013) Solid-state NMR on bacterial cells: selective cell wall signal enhancement and resolution improvement using dynamic nuclear polarization. J Am Chem Soc 3:1-9. doi:10.1021/ja312501d
Van Dalen A, Schrempf H, Killian JA, de Kruijff B (2000) Efficient membrane assembly of the KcsA potassium channel in Escherichia coli requires the protonmotive force. EMBO Rep 1:340-346. doi:10.1093/embo-reports/kvd067

Van der Cruijsen EAW, Nand D, Weingarth M et al (2013) Importance of lipid-pore loop interface for potassium channel structure and function. Proc Natl Acad Sci USA 110:13008-13013. doi:10. 1073/pnas. 1305563110

Wang T, Zabotina O, Hong M (2012) Pectin-cellulose interactions in the Arabidopsis primary cell wall from two-dimensional magicangle-spinning solid-state nuclear magnetic resonance. Biochemistry 51:9846-9856. doi:10.1021/bi3015532

Wang S, Munro RA, Shi L et al (2013a) Solid-state NMR spectroscopy structure determination of a lipid-embedded heptahelical membrane protein. Nat Methods 10:1007-1012

Wang S, Shi L, Okitsu T et al (2013b) Solid-state NMR ${ }^{13} \mathrm{C}$ and ${ }^{15} \mathrm{~N}$ resonance assignments of a seven-transmembrane helical protein Anabaena Sensory Rhodopsin. Biomol NMR Assign 7:253-256

Wang T, Salazar A, Zabotina OA, Hong M (2014) Structure and dynamics of Brachypodium primary cell wall polysaccharides from twodimensional (13)C solid-state nuclear magnetic resonance spectroscopy. Biochemistry 53:2840-2854. doi:10.1021/bi500231b

Ward ME, Wang S et al (2015) In situ structural studies of Anabaena Sensory Rhodopsin in the E. coli membrane. Biophys J 108:1683-1696

Wei Y, de Dios AC, McDermott AE (1999) Solid-state 15N NMR chemical shift anisotropy of histidines: experimental and theoretical studies of hydrogen bonding. J Am Chem Soc 121:10389-10394

Weingarth M, Baldus M (2013) Solid-state NMR-based approaches for supramolecular structure elucidation. Acc Chem Res 46:2037-2046. doi:10.1021/ar300316e

Weingarth M, Demco DE, Bodenhausen G, Tekely P (2009) Improved magnetization transfer in solid-state NMR with fast magic angle spinning. Chem Phys Lett 469:342-348

Weingarth M, Prokofyev A, van der Cruijsen EAW et al (2013) Structural determinants of specific lipid binding to potassium channels. J Am Chem Soc 135:3983-3988. doi:10.1021/ja3119114

Yamamoto K, Caporini MA, Im S-C et al (2014) Cellular solid-state NMR investigation of a membrane protein using dynamic nuclear polarization. Biochim Biophys Acta. doi:10.1016/j.bbamem.2014. 07.008

Zhou H-X, Cross TA (2013) Influences of membrane mimetic environments on membrane protein structures. Annu Rev Biophys 42:361-392 